\title{
Gender Role Study in Participatory Variety Selection of Bread Wheat in Potential Growing Areas of Arsi in Ethiopia
}

\author{
Sakatu Hunduma \\ Ethiopian Institute of Agricultural Research, P.O.Box, 2003, Addis Ababa, Ethiopia
}

\begin{abstract}
Field experiment was carried out on three locations Dera, Iteya and Bekoji in Arsi zone of Ethiopia for two years (2012 \& 2013) to study gender role in variety selection. Individual farmers and breeders independently carried out visual selection of bread wheat varieties on field condition at maturity stage at each locations. Twenty one released bread wheat varieties were taken and planted for the study. Breeders and Twenty wheat producing farmers selected from each locations in which ten of them were women farmers and ten were men farmers carried out the variety selection for specific agro ecologies based on their own selection criteria. According to the result of this study both male and female farmers are equally important to select best wheat variety for their own agro ecology. Out of the first ten selected wheat varieties for each location more than half of them are selected both by male and female farmers in common. In other case, both male and female farmers were specific on some varieties, that means there was a variety which is only selected either by male or by female farmers. This may be related to difference in roles and responsibilities of men and women in a given house hold. Similarly there are also some varieties which are selected only by breeders in each locations in which neither male nor female farmers are selecting those varieties. In conclusion, besides breeders selection, considering the preference of both male and female farmers equally and inclusion of quality taste in our variety selection \& releasing procedure may improve the adoption rate of Bread wheat varieties. Not only for variety selection but also in all of our research work without considering gender role, our research results may be concluded wrongly and we cannot achieve sustainable agricultural development.
\end{abstract}

Keywords: Gender role, participatory variety selection, Bread wheat, Improved variety

DOI: $10.7176 / \mathrm{JCSD} / 63-03$

Publication date: January $31^{\text {st }} 2021$

\section{Introduction}

The rationale for considering gender in agricultural research relates to agricultural productivity, food security, nutrition, poverty reduction, and empowerment. In all of these cases, women play a critical, but often under recognized, role and face greater constraints than men. When it comes to disaggregating gender roles in agricultural activities, its necessity is often not given due attention at the decision makers level. Gender equality requires equal enjoyment by women and men of socially-valued goods, opportunities, resources and rewards. Men and women within households do not have the same preferences nor pool their resources (Alderman et al.,1996; Haddad et al.,1997). The low adoption rate of many of the crop varieties, especially in subsistence and small scale farming systems, has been attributed to the release of station-bred varieties that were evaluated and managed by researchers under conditions that are most favorable to crop growth without regard to local constraints and farmers (Gyawali et al., 2007; Weltzien et al., 2003).

More recently, plant breeding strategies that make use of, and maintain crop diversity have been advocated by some researchers as one way of improving crop yields, productivity, stability, and adoption rate (Witcombe et al., 1996; Mekbib, 2006). participatory variety selection is one of such strategy that aims at strengthening cooperation between researches, especially breeders, and farmers in evaluating plant germplasm and establishing plant breeding goals that take into account farmers' knowledge and gender factors. agronomic, socio-economic, and socio-cultural requirements of smallholder farmers and consumers are too diverse to be filled by a limited number of genotypes (Witcombe et al., 1996). Efforts to develop agriculture in a manner that will benefit the poor must fully address gender equality and the empowerment of women. The role of gender in decision-making for varietal selection and adoption is very much influenced by the type of community.

Sex-disaggregated data, gender analysis, and women's participation in decision-making are necessities in agricultural planning and implementation, including development of new varieties. Selection with farmers is extremely useful for decentralizing breeding programs (Gyawali et al., 2007). This research work was planned to study gender role in participatory variety selection of bread wheat at the study area.

\section{Materials and Methods}

Field experiment was carried out on three locations Dera, Iteya and Bekoji in Arsi zone of Ethiopia for two years (2012 \& 2013). Individual farmers and breeders independently carried out visual selection of bread wheat varieties at each site. Twenty one released bread wheat varieties (Danda'a, Kakaba, Hawi ,Tusie, Paven-76, ET-13A2, K6295-4A, ETBW 5483, ETBW 5496, Digelu, Sofumar, MadaWalabu, Tay , Senkegna, Gasay, Menze , Bolo, Alidoro, Dinknesh, Tossa and kulkulu) were taken and planted for the study. The design of the experiment was 
RCBD with two replication and implemented at three locations. The net plot area was $3 \mathrm{~m}^{2}$.

Twenty wheat producing farmers were selected from each locations in which ten of them were women farmers and ten were men farmers to carried out the variety selection. Then farmers were invited to select bread wheat varieties based on their own criteria using a $0-4$ scale, where 0 means very poor, 1 means poor, 2 means fair, 3 means good and 4 means very good. Breeders also carried out the selection based on their own criteria at a time to compare their selection with farmers selection at each areas during the study time. Bread wheat variety selection was carried out on field condition at maturity stage at each location.

\section{Result and Discussions}

As indicated in the methodology twenty one bread wheat varieties were planted at three locations having different agro ecology named 'Dera' which was low land area, 'Iteya' was mid highland and 'Bekoji' was highland area. At each location breeders and Male and female farmers were carried out variety selection based on their own criteria and rank varieties for their own specific location. Out of twenty one bread wheat varieties the first ten selected varieties were considered in this research result and discussion.

Table 1: Bread wheat varieties selected for 'Dera' location for two years

\begin{tabular}{|c|c|l|c|l|c|l|}
\hline Selectors & \multicolumn{3}{|c|}{ Female farmers } & \multicolumn{2}{c|}{ Male farmers } & \multicolumn{1}{c|}{ Breeders } \\
\hline Rank & Year1 & \multicolumn{1}{|c|}{ Year2 } & Year1 & Year2 & Year1 & \multicolumn{1}{|c|}{ Year2 } \\
\hline 1 & Paven-76 & Tay & Digelu & Alidoro & Bolo & Alidoro \\
\hline 2 & Menze & Sofumar & Menze & Sofumar & shorima & huluka \\
\hline 3 & huluka & Alidoro & Bolo & huluka & Senkegna & Danda'a \\
\hline 4 & kulkulu & kulkulu & kulkulu & Tay & Menze & Tay \\
\hline 5 & shorima & Danda'a & Danda'a & kulkulu & Kakaba & Sofumar \\
\hline 6 & Bolo & Gasay & shorima & Senkegna & Paven-76 & kulkulu \\
\hline 7 & Tay & huluka & Tossa & Danda'a & Alidoro & Paven-76 \\
\hline 8 & Danda'a & Digelu & huluka & Paven-76 & Danda'a & Senkegna \\
\hline 9 & Mada-Walabu & Senkegna & Alidoro & Digelu & huluka & Gasay \\
\hline 10 & Sofumar & Paven-76 & Kakaba & Gasay & Digelu & Kakaba \\
\hline
\end{tabular}

All selectors (Female \& Male farmers and Breeders) were involved to select best suit bread wheat varieties for low land areas at 'Dera' research site based on their own criteria. The first ten varieties selected by female and male farmers as well as breeders were listed separately (Table 1). The result of the selection showed that both male and female farmers repeatedly select three varieties (Kulkulu, Huluka and Danda'a) in common for low land areas (Table 1). Out of the first ten varieties selected for the low land areas more than half of them were selected both by male and female farmers which indicated that women farmers are equally important as male farmers to select verities for their location.

Table 2: Bread wheat varieties selected for 'Iteya' location for two years

\begin{tabular}{|c|c|c|c|c|c|c|}
\hline \multirow{2}{*}{$\begin{array}{c}\text { Selectors } \\
\text { Rank }\end{array}$} & \multicolumn{2}{|c|}{ Female farmers } & \multicolumn{2}{|c|}{ Male farmers } & \multicolumn{2}{|c|}{ Breeders } \\
\hline & Year1 & Year2 & Year1 & Year2 & Year1 & Year2 \\
\hline 1 & huluka & Dinknesh & Tay & Dinknesh & Danda'a & Danda'a \\
\hline 2 & Tay & Danda'a & kulkulu & Danda'a & huluka & Tay \\
\hline 3 & kulkulu & $\begin{array}{l}\text { Mada- } \\
\text { Walabu }\end{array}$ & huluka & Kakaba & Tay & Gasay \\
\hline 4 & shorima & Kakaba & Danda'a & Tay & Senkegna & Mada-Walabu \\
\hline 5 & Senkegna & Tay & Gasay & Bolo & Gasay & Digelu \\
\hline 6 & Digelu & kulkulu & Digelu & $\begin{array}{l}\text { Mada- } \\
\text { Walabu }\end{array}$ & kulkulu & Menze \\
\hline 7 & Alidoro & Bolo & Senkegna & Digelu & Kakaba & Kakaba \\
\hline 8 & Danda'a & Sofumar & Menze & Sofumar & shorima & Tusie \\
\hline 9 & Tusie & shorima & shorima & Menze & Digelu & shorima \\
\hline 10 & Gasay & Digelu & Tusie & Senkegna & Paven-76 & Sofumar \\
\hline
\end{tabular}

In this research trial 'Iteya' represents the mid highland areas of Arsi zone and farmers selected from this area were also carried out bread wheat varieties best suit for mid highland areas by the selection done at 'iteya' site. All selectors (Female \& Male farmers and Breeders) were involved to select best suit bread wheat varieties for mid highland areas at 'Iteya' research location based on their own criteria. The first ten varieties selected by female and male farmers as well as breeders were listed separately (Table 2). According to the selection result both male and female farmers repeatedly select three varieties (Digelu, Tay and Danda'a) in common for mid highland areas. Out of the first ten varieties selected for the mid highland areas more than half of them were selected both by male and female farmers which indicated that women farmers are equally important as male farmers to select verities 
for their location (Table 2).

Table 3: Bread wheat varieties selected for 'Bekoji' location for two years

\begin{tabular}{|c|c|l|c|l|c|l|}
\hline Selectors & \multicolumn{2}{|c|}{ Female farmers } & \multicolumn{2}{|c|}{ Male farmers } & \multicolumn{2}{c|}{ Breeders } \\
\hline Rank & Year1 & Year2 & Year1 & Year2 & Year1 & Year2 \\
\hline 1 & Danda'a & Alidoro & Danda'a & Digelu & Senkegna & Digelu \\
\hline 2 & huluka & Digelu & Menze & Menze & Danda'a & Mada-Walabu \\
\hline 3 & Sofumar & Menze & kulkulu & Tusie & Digelu & Paven-76 \\
\hline 4 & Senkegna & Tusie & huluka & Bolo & Tay & Danda'a \\
\hline 5 & Menze & ET-13A2 & Tay & Alidoro & Menze & Tusie \\
\hline 6 & kulkulu & Tay & Sofumar & ET-13A2 & kulkulu & huluka \\
\hline 7 & Bolo & Senkegna & Senkegna & Tay & huluka & Alidoro \\
\hline 8 & shorima & Gasay & Alidoro & huluka & Mada-Walabu & Tay \\
\hline 9 & Digelu & Danda'a & shorima & Danda'a & Alidoro & Menze \\
\hline 10 & Tay & Kakaba & Bolo & Sofumar & Tusie & Bolo \\
\hline
\end{tabular}

In the research trial 'Bekoji' represents the highland areas of Arsi zone and farmers selected from this area were also carried out bread wheat varieties best suit for highland areas by the selection done at 'Bekoji' site. All selectors (Female \& Male farmers and Breeders) were involved to select best suit bread wheat varieties for mid highland areas at 'Bekoji' research location based on their own criteria. The first ten varieties selected by female and male farmers as well as breeders were listed separately (Table 3). Both male and female farmers repeatedly select three varieties (Menze, Tay and Danda'a) in common for mid highland areas (Table 3).

According to this selection result both male and female farmers are specific on some varieties, that means there was a variety which is only selected either by male or by female farmers ( Table 4) which may be related to their difference in roles and responsibilities. Regardless of their location, female farmers of the three study locations repeatedly select bread wheat variety named 'Tay' in common both years ( Table 4). In addition Both male and female farmers of the study area regardless of their difference in gender and location they select the variety named 'Danda'a' for thier location ( Table 4).

Table 4: Consistency of Selectors on bread wheat variety selection at each locations

\begin{tabular}{|c|c|c|c|c|c|c|c|}
\hline \multirow[b]{3}{*}{ No } & \multirow{3}{*}{ Selectors } & \multicolumn{6}{|c|}{ Location } \\
\hline & & \multicolumn{2}{|c|}{ Dera (Low land area) } & \multicolumn{2}{|c|}{ Iteya (Mid highland area) } & \multicolumn{2}{|c|}{ Bekoji (Highland area) } \\
\hline & & Selected once & $\begin{array}{l}\text { Repeatedly } \\
\text { selected }\end{array}$ & Selected once & $\begin{array}{l}\text { Repeatedly } \\
\text { selected }\end{array}$ & Selected once & $\begin{array}{l}\text { Repeatedly } \\
\text { selected }\end{array}$ \\
\hline 1 & $\begin{array}{l}\text { Female } \\
\text { farmers }\end{array}$ & $\begin{array}{l}\text { Menze, } \\
\text { Shorima, Bolo, } \\
\text { Mada-alabu, } \\
\text { Alidoro, } \\
\text { Gasay, Digelu, } \\
\text { Senkegna, }\end{array}$ & $\begin{array}{l}\text { Kulkulu, } \\
\text { Danda'a, } \\
\text { Huluka, } \\
\text { Paven- } \\
\text { 76,Tay, } \\
\text { Sofumar, }\end{array}$ & $\begin{array}{l}\text { Huluka } \\
\text { Dinknesh, Mada- } \\
\text { Walabu } \\
\text { Kakaba, } \\
\text { Senkegna,Bolo, Sof } \\
\text { umar,Alidoro, } \\
\text { Tusie, Gasay, }\end{array}$ & $\begin{array}{l}\text { Danda'a } \\
\text { Digelu, Tay } \\
\text { Kulkulu, } \\
\text { Shorima }\end{array}$ & $\begin{array}{l}\text { Alidoro,Kaka } \\
\text { ba,Tusie,ET- } \\
\text { 13A2,Kulkul } \\
\text { u,Bolo,Shori } \\
\text { ma,Gasay,Hu } \\
\text { luka,Sofumar }\end{array}$ & $\begin{array}{l}\text { Danda'a } \\
\text { Senkegna } \\
\text { Menze } \\
\text { Digelu } \\
\text { Tay }\end{array}$ \\
\hline 2 & $\begin{array}{l}\text { Male } \\
\text { farmers }\end{array}$ & $\begin{array}{l}\text { Sofumar,shori } \\
\text { ma,Tossa,Kaka } \\
\text { ba,Gasay,Pave } \\
\text { n- } \\
\text { 76,Senkegna,T } \\
\text { ay,Menze,Bolo }\end{array}$ & $\begin{array}{l}\text { Digelu, } \\
\text { Huluka, } \\
\text { Alidoro, } \\
\text { Kulkulu } \\
\text { Danda'a, }\end{array}$ & $\begin{array}{l}\text { Dinknesh, kulkulu } \\
\text { Huluka, Kakaba } \\
\text { Gasay, Bolo } \\
\text { Mada- Walabu, } \\
\text { Sofumar, Shorima, } \\
\text { Tusie, }\end{array}$ & $\begin{array}{l}\text { Danda'a, } \\
\text { Tay,Digelu, } \\
\text { Menze, } \\
\text { Senkenya }\end{array}$ & $\begin{array}{l}\text { Digelu, } \\
\text { Kulkulu. } \\
\text { Tusie,ET- } \\
13 \mathrm{~A} 2 \\
\begin{array}{l}\text { Senkegna,Sh } \\
\text { orima }\end{array}\end{array}$ & $\begin{array}{l}\text { Danda'a } \\
\text { Menze } \\
\text { Bolo,Alidoro, } \\
\text { Huluka } \\
\text { Tay } \\
\text { Sofumar }\end{array}$ \\
\hline 3 & Breeders & $\begin{array}{l}\text { Bolo, Shorima, } \\
\text { Menze,Tay } \\
\text { Sofumar } \\
\text { Kulkulu, } \\
\text { Gasay, Digelu }\end{array}$ & $\begin{array}{l}\text { Senkegna, } \\
\text { Kakaba, } \\
\text { Paven- } \\
\text { 76,Alidor } \\
\text { o,Danda'a, } \\
\text { Huluka, }\end{array}$ & $\begin{array}{l}\text { Huluka,Senkegna, } \\
\text { Mada-Walabu, } \\
\text { Kulkulu,Menze, } \\
\text { Tusie,Paven- } \\
\text { 76,Sofumar, }\end{array}$ & $\begin{array}{l}\text { Danda'a, Tay, } \\
\text { Gasay, } \\
\text { Kakaba, } \\
\text { Shorima, } \\
\text { Digelu }\end{array}$ & $\begin{array}{l}\text { Senkegna } \\
\text { Kulkulu,Pave } \\
\text { n-76 } \\
\text { Bolo }\end{array}$ & $\begin{array}{l}\text { Danda'a } \\
\text { Digelu, Tay } \\
\text { Menze } \\
\text { Huluka } \\
\text { Mada-Walabu } \\
\text { Alidoro Tusie }\end{array}$ \\
\hline
\end{tabular}

There are also some varieties selected by breeders for a given location in a condition those varieties were not selected neither by male nor by female farmers of the area. Varieties named: Paven-76 at Iteya site and Madawalabu and Paven-76 at Bekoji location were selected for those areas by breeders but those varieties were neither selected by male nor female farmers. 
Table 5: Farmer's Selection criteria documented for the Wheat variety selection carried out on field condition based on their specific agro ecology

\begin{tabular}{|l|l|l|l|}
\hline & Low land (Dera) & Mid highland (Iteya) & Highland (Bekoji) \\
\hline $\begin{array}{l}\text { Male farmer's } \\
\text { Selection criteria }\end{array}$ & $\begin{array}{l}\text { Having medium number of } \\
\text { tillers, medium plant height, } \\
\text { Uniform plant stand the } \\
\text { plant population have to } \\
\text { cover the land) } \\
\text { Early matured \& } \\
\text { not easily shattered }\end{array}$ & $\begin{array}{l}\text { Free } \\
\text { symptom(relatively not } \\
\text { highly infected) } \\
\text { High y } \\
\text { relatively large number of } \\
\text { seed per spike) } \\
\text { Not shattered, Uniform } \\
\text { maturity }\end{array}$ & $\begin{array}{l}\text { Lodging resistant } \\
\text { Good tillering capacity, } \\
\text { Late in maturity } \\
\text { Short to Medium plant } \\
\text { height, not easily shattered, } \\
\text { Good plant stand }\end{array}$ \\
\hline $\begin{array}{l}\text { Female farmer's } \\
\text { Selection criteria }\end{array}$ & $\begin{array}{l}\text { Having high grain and straw } \\
\text { yield, Early mature, during } \\
\text { Not shattered } \\
\text { harvesting }\end{array}$ & $\begin{array}{l}\text { Having high grain and straw } \\
\text { yield, Early mature, Not } \\
\text { shattered during harvesting }\end{array}$ & $\begin{array}{l}\text { Relatively less infected by } \\
\text { rust disease, long spike }\end{array}$ \\
\hline
\end{tabular}

\section{Conclusions and Recommendations}

The current study was carried out to study the gender difference in wheat variety selection. According to the result of this study both male and female farmers are equally important to select best wheat variety for their own agro ecology. In other case, both male and female farmers are specific on some varieties, that means there was a variety which is only selected either by male or by female farmers in which this may be related to their difference in roles and responsibilities of men and women in a given house hold. Similarly there are also some varieties which are selected only by breeders in each locations in which neither male nor female farmers are selecting those varieties. In conclusion, considering the preference of both male and female farmers equally and inclusion of quality taste in our variety selection and releasing procedure may improve the adoption rate of Bread wheat varieties. Not only for variety selection but also in all of our research work without considering gender role, our research results may be concluded wrongly. Considering the gender role in our research study helps achieving sustainable agricultural development in general.

\section{Acknowledgments}

Kulumsa Agricultural Research Center is acknowledged for all the logistics and managerial support provided during the experimental period. Great thanks go to wheat Improvement Research Team for their valuable assistance.

\section{Funding}

East African Agricultural Productivity Project (EAAPP), is acknowledged for financial support for the experiment.

\section{References}

Alderman, H., L. Haddad, and C. Udry. 1996. Gender differentials in farm productivity: Implications for household efficiency and agricultural policy. Food Consumption and Nutrition Division Discussion Paper 6. Washington, D.C.: IFPRI.

Gyawali S, Sunwar S, Subedi M, Tripathi M, Joshi KD, Witcombe JR (2007). Collaborative breeding with farmers can be effective. Field Crop Res., (101): 88-95.

Haddad, L., J. Hoddinott, and H. Alderman, eds. 1997. Intrahousehold resource allocation in developing countries: Models, methods, and policy. Baltimore, MD: Johns Hopkins University Press for the IFPRI.

Mekbib F (2006). Farmer and formal breeding of sorghum (Sorghum bicolor (L.) Moench) and the implications for integrated plant breeding. Euphytica, 152 (2): 163-176.

Weltzien E, Smith ME, Meitzner LS, Sperling L (2003). Technical and institutional issues in participatory plant breeding- from the perspective of formal plant breeding. A global analysis of issues, results, and current experiences. CGIAR systemwide program on participatory research and gender analysis for technology development and institutional innovation. CIAT. PPB monograph No. 1. p. 208

Witcombe, J.R., Joshi, A., Joshi, K.D. and Sthapit, B.R. 1996. Farmer participatory crop improvement. I: Varietal selection and breeding methods and their impact on biodiversity. Experimental Agriculture 32:445-460. 